\title{
Primary bilateral uveal melanoma: A case report
}

\author{
Federica Genovesi Ebert ${ }^{1 *}$, Francesca Guido ${ }^{1}$, Federica Cresti ${ }^{1}$, Franco Perrone ${ }^{2}$ and Maria Grazia Fabrini $^{2}$ \\ ${ }^{1}$ Ophthalmic Surgery Department, University of Pisa, 2 Via Paradisa, Pisa, Italy \\ ${ }^{2}$ Department of Radiotherapy, University of Pisa, 57 Via Roma, Pisa, Italy
}

\begin{abstract}
The aim of this case report was to describe a rare case of primary bilateral uveal melanoma. A 51 years old male with family history of cancer (breast, lung and bowel cancer) attended our Ocular Oncology Center of Pisa on December 2010 suffering from ocular hypertension in the right eye. Ultrabiomicroscopy (UBM) revealed a solid lesion of the ciliary body in inferior-temporal quadrant and cysts with low reflectivity content. The cysts were localized behind the iris and surrounded the ciliary body. Brachytherapy with Ruthenium-106 plaque was performed. Four years later patient presented metamorphopsia and phosphenes in the left eye. Ultrasound examination revealed a temporal mushroom shaped lesion with exudative retinal detachment. A combined treatment of brachytherapy with Ruthenium 106 plaque and stereotactic radiotherapy were performed in the left eye. Primary bilateral uveal melanoma is extremely rare but is a possible occurrence and should therefore be considered in the management of patients with primary uveal melanoma.
\end{abstract}

\section{Introduction}

Uveal melanoma (UM) is the most frequent primary intraocular malignancy in the adult. The incidence of UM in the USA is 4.3 per million with a prevalence in males. $97,8 \%$ of the registered cases occurred in white population [1]. There is a strong difference in the incidence for different ethnic groups but prognosis does not vary [2,3]. Primary bilateral uveal melanoma is exceedingly rare and only case reports or short series have been reported in the literature. Jeffrey Scott et al described in a review a total of 52 cases of primary bilateral UM from three combined data sources [4]. No clinical evidence of inherited genetic predisposition was found although ocular melanocytosis was more common in those patients [5]. We describe the presentation and outcome of a patient with primary bilateral uveal melanoma.

\section{Case report}

A 51 years old, man, was referred to our observation because of the ocular hypertension in the right eye on December 2010. The patient had a family history of cancer (breast, lung and bowel cancer). Slit lamp examination revealed a normal external eye conjunctiva and cornea, pupil was round and reaching to light.

Ultrabiomicroscopy (UBM) examination of the right eye was performed with a $50 \mathrm{MHz}$ probe and revealed a solid lesion of the ciliary body in the inferior-temporal quadrant and cysts with low reflectivity content. The cysts were behind the iris and surrounding the ciliary body. An initial cataract, resulting from the contact with the lesion was also noted. Left eye showed no alteration. Maximun thickness of the lesion, including sclera was $3.5-4$ millimeters $(\mathrm{mm})$ and the basal diameter was $7 \mathrm{~mm}$ (Figure 1). Patient was treated with Rutenium-106 plaque brachytherapy on December $20^{\text {th }}, 2010$ and 110 Gray (Gy) at the tumor apex was administered. Plaque was removed on December $23^{\text {rd }}, 2010$.

Clinical and instrumental examinations showed the progressive reduction of the lesion. UBM performed on November $27^{\text {th }}, 2013$ revealed a thickness of 2,25 mm (Figure 2). The intraocular pression in the right eye was kept under control with topical therapy. Regular systemic assessments including abdominal ultrasound and chest RX were performed and patient was healthy with no sign of systemic metastatic disease.

On January 2014 cataract surgery was performed on the right eye with good visual recovery. Best corrected visual acuity (BCVA) was $20 / 20$, Log mar $=0$. At the time of the surgery left eye examination showed BCVA 20/20 and only mild myopic alteration at fundus examination.

On November 2014 patient suffered from sudden metamorphopsia and phosphenes in the left eye. At the examination BCVA was 20/40 and slit lamp examination revealed a normal external eye, conjunctiva

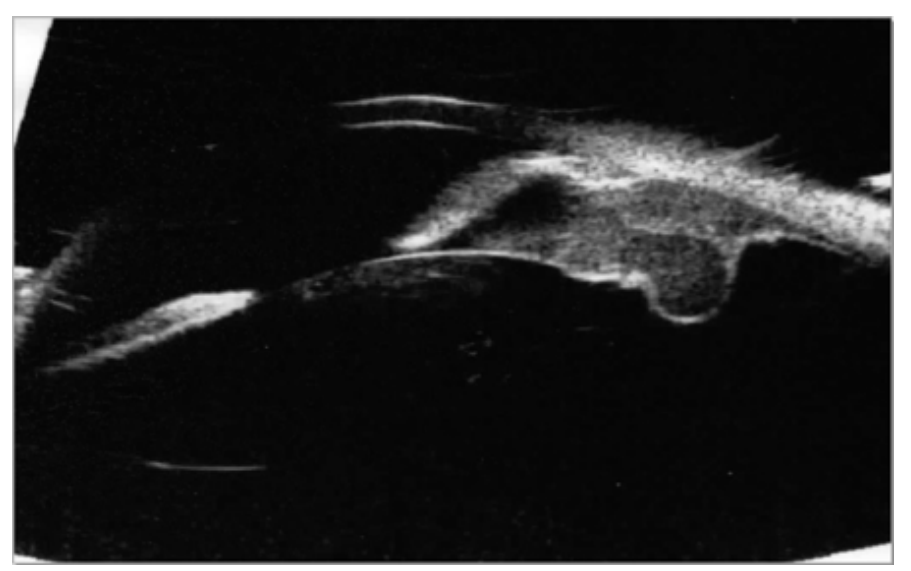

Figure 1. Ultrabiomicroscopy. the solid lesion of the ciliary body before treatment. The tumor pushing the lens caused cataract

${ }^{\star}$ Correspondence to: Federica Genovesi Ebert, Ophthalmic Surgery Department, University of Pisa, 2 Via Paradisa, Pisa, Italy, E-mail: federica.genovesiebert@ gmail.com

Key words: uveal melanoma, bilateral, brachytherapy, stereotactic radiotherapy

Received: May 24, 2020; Accepted: July 13, 2020; Published: July 17, 2020 
and cornea but revealed a mushroom shaped lesion in the temporal quadrant with scarce pigmentation and superficial haemorrhage. B-scan and A-scan Standardized Echography of the left eye was performed (with a $10 \mathrm{MHZ}$ and $20 \mathrm{MHZ}$ probe) showing an exophytic amelanotic 'mushroom shaped' lesion with low internal reflectivity, regular structure , 11,95 $\mathrm{mm}$ in thickness, $13,88 \mathrm{~mm}$ in basal diameter, with exudative retinal detachment (Figure 3).

Fluorescein and indocyanine Angiography (FA + ICG-A) was performed and displayed the presence of an irregularly pigmented choroidal lesion and an hyperfluorescence with atypical circulation (Figures $4 \mathrm{~A}$ and $4 \mathrm{~B}$ ). Optical coherence tomography showed a detachment of the neuroepithelium (Figure 5).

A careful systemic evaluation including PET/CT scan failed to demonstrate any other primary or secondary tumor. Then BCVA deteriorated to $20 / 400$ due to vitreous haemorrhage. The patient underwent combined brachytherapy in order to safely perform fine needle biopsy, and subsequently Stereotactic Radiotherapy. On November $27^{\text {th }}, 2014$, fine needle aspiration biopsy (FNAB) and Ruthenium-106 plaque brachytherapy were performed (85 Gy were administered). FNAB showed atypical cells in small groups, with epithelial morphology and presence of melanic pigmentation. Immunoistochemical coloration was positive. On January $5^{\text {th }}, 2015$, Stereotactic Radiotherapy with Volumetric-Modulated Arc Therapy (VMAT) using TrueBeam STx linear acceleration with 6 MV FFF photon beams was performed (25 Gy were delivered in a single fraction). After treatment Visual Acuity of left eye was hand motion

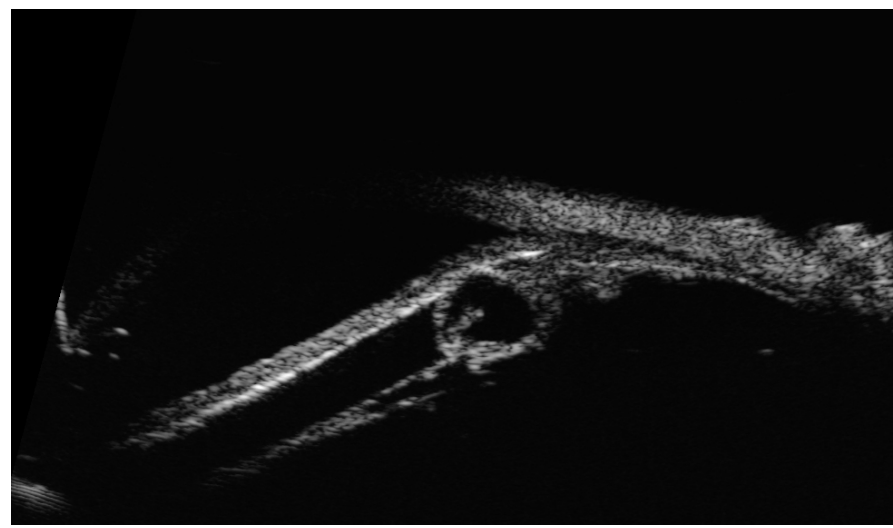

Figure 2. Ultrabiomicroscopy after treatment with a reduction of the lesion size

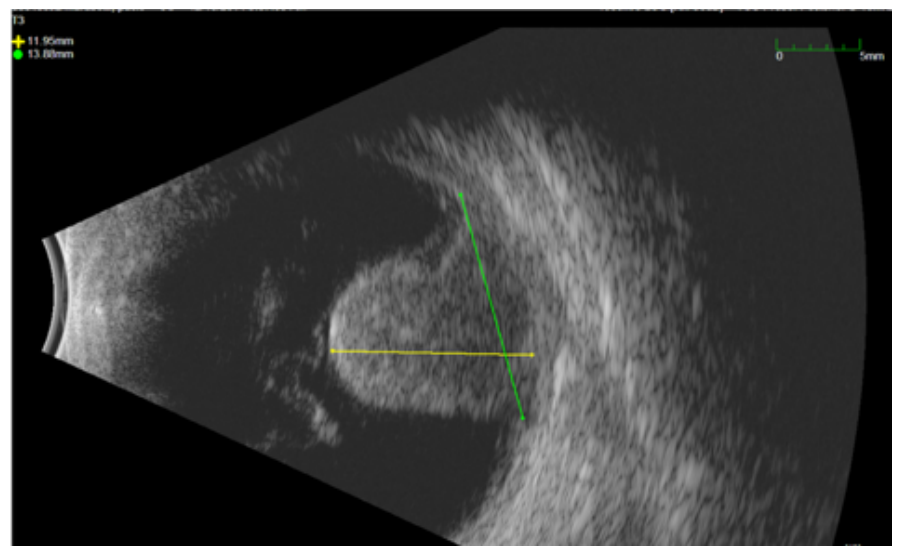

Figure 3. B scan Ultrasonography. Temporal mushroom shaped lesion with retinal exudative detachment

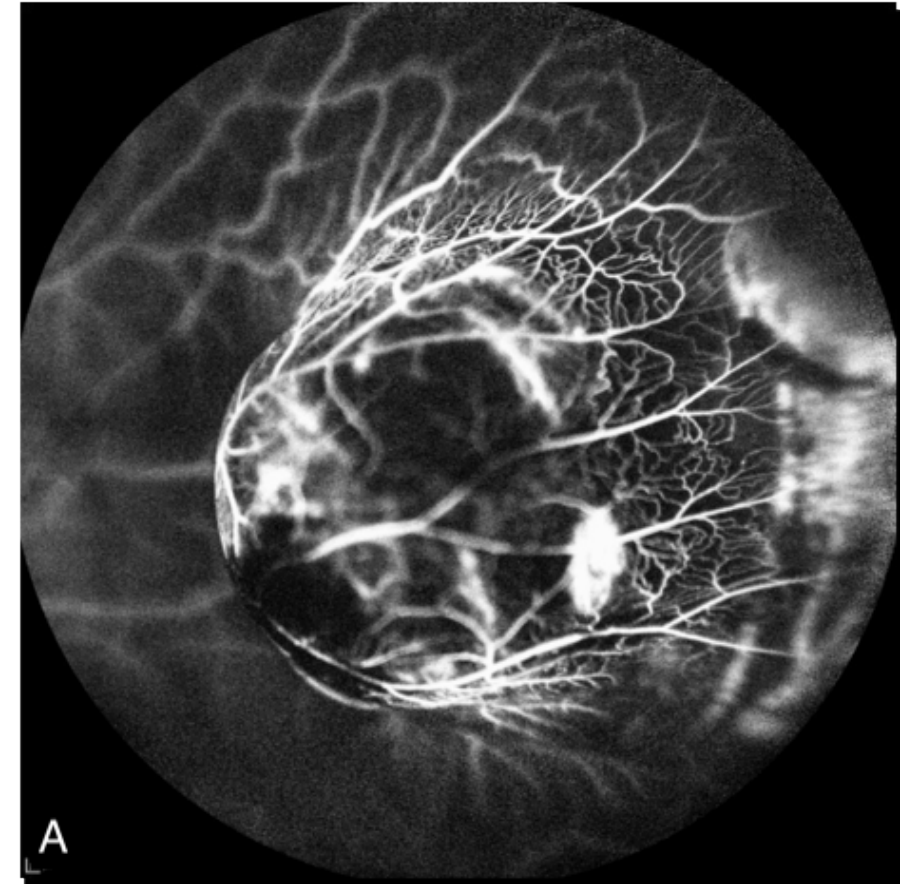

Figure 4A. Fluorescein Angiography. irregularly pigmented choroidal lesion

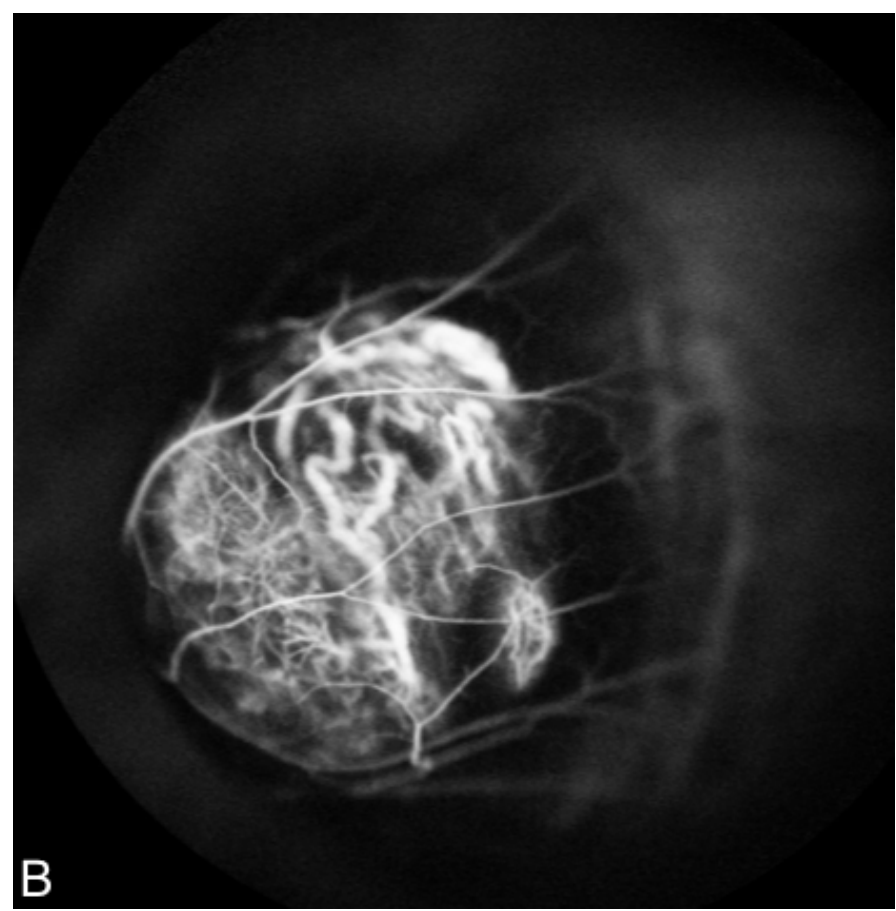

Figure 4B. Indocyanine Angiography showed irregular hyperfluorescence with atypica circulation

(due to persistent vitreous haemorrhage), thickness lesion was 4,6 mm (Figure 6). An intravitreal injection of bevacizumab was performed.

On April 23 ${ }^{\text {rd }}, 2018$ cataract surgery and pars plana vitrectomy (PPV) with polydimethylsiloxane (PDMS) for vitreous haemorrhage was performed. On July $25^{\text {th }}, 2018$, liver lesions compatible with melanoma metastasis were discovered during follow-up visit (Figure 7). On August $30^{\text {th }}$, the patient begun immunotherapy with Nivolumab (anti PD1) 480 


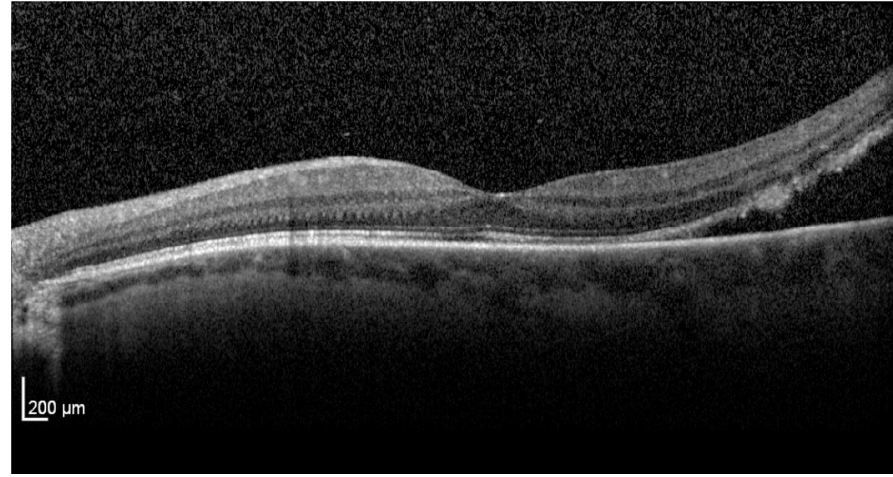

Figure 5. Optic Coherence Tomography showed a neuroepithelium detachment

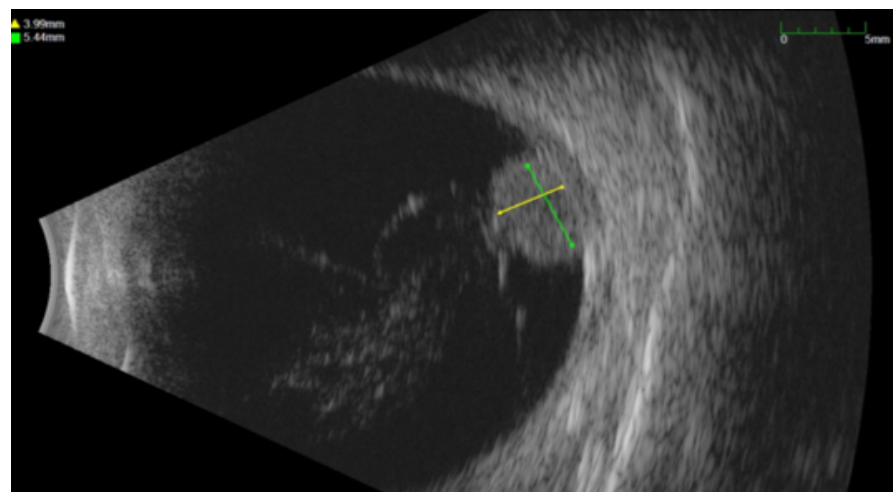

Figure 6. Thickness' reduction of the lesion after brachytherapy and subsequently Stereotactic Radiotherapy

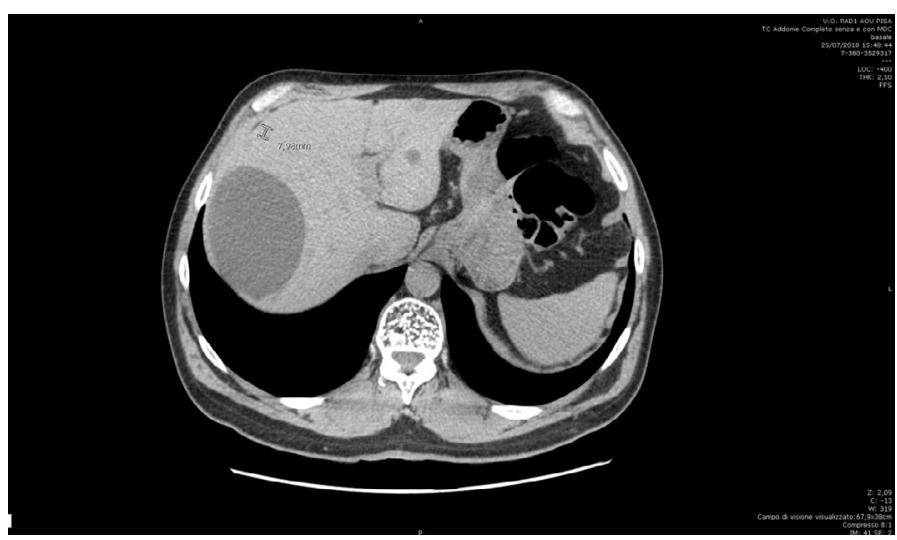

Figure 7. CT scan. Liver lesions compatible with melanoma metastases

mg every 28 days. On November $22^{\text {nd }}, 2018$ he completed fourth cycle of immunotherapy. On December $13^{\text {th }}$ silicon oil was removed due to uncontrolled intraocular pressure. Subsequently patient developed anterior chamber and vitreous haemorrhage.

Total Body CT scan was performed on January 9th, 2019 and showed a poor response to immunotherapy and the appearance of multiple vertebral bone lesions compatible with other metastases. The patient is still alive with stable systemic condition. At the last follow-up examination performed May 10,2020 right eye BCVA was 20/20, while left eye showed no light perception.

\section{Discussion}

Primary bilateral uveal melanoma is extremely rare. In the United States one of the first cases of bilateral UM was reported in 1959 by
Wiesinger [6]. In this single ocular oncology center during 20 years were followed about 4500 patients with uveal melanoma and less than $0.2 \%$ presented bilateral UM [5]. Due to poor cases reported the characteristics of primary bilateral UM and how they are related to unilateral UM were not been clarified. Jeffrey Scott et al described in a review a total of 52 cases of primary bilateral UM from three combined data sources. This review demonstrated that the development of bilateral disease does not predict a poorer prognosis. Patients with bilateral UM had similar survival as unilateral patients [4].

Five-years relative survival of UM patients was $68,9 \%, 81.6 \%$ and $81.4 \%$ for cases diagnosed in Europe, the USA and Western Australia respectively [7-9]. Since the conservative treatment is performed it has been noticed that patients survival has not improved [8].

Collaborative ocular melanoma study group reported that $25 \%$ and $34 \%$ of UM patients developed metastases within 5 and 10 years, respectively [10].It has been noticed that the mean survival after diagnosis of metastatic UM is approximately 1 year $[11,12]$ but some patients survive more than 4 years [13]

At present there is no approved adjuvant therapy for UM but there are about 69 trials $[14,15]$. Ocular melanocytosis may represent a risk factor for uveal melanoma, furthermore was revealed in patients with bilateral UM more frequently with those with unilateral UM $[5,16]$. Our patient didn't show ocular melanocitosys. The mean age at diagnosis of the first affected eye in the patients with bilateral involvement was similar from that of unilateral patients ( 56 and 59 years respectively). According to the results obtained by Singh et al [5] the average interval between the diagnosis of uveal melanoma in the two eyes is 10.5 years. Our patient developed the second uveal melanoma 4 years after the first diagnosis.

In the present case report the localization was different for the two melanomas as in the first eye the ciliary body was involved, while in the second eye the tumor was localized in the choroid. Also, the prognosis was different as the RE at the last follow-up examination was still 20/20, while in the LE deteriorated to no light perception.

Bilaterality of a primary cancer in a paired organ may suggests a genetic predisposition. Eide et al described a case of primary bilateral UV with displayed chromosomal aneuploid suggestive of discordant BAP1 expression in each affected eye [17]. Two other cases of primary bilateral uveal melanoma with a pathogenic mutation in BAP1 have recently been reported [18].

Other study is necessary to demonstrates if there is a correlation between genetic predisposition and bilateral uveal melanoma or if is a random event. In conclusion bilateral uveal melanoma is a possible occurrence, although rare, and should therefore be carefully considered in the management of patients with primary uveal melanoma.

\section{Funding}

None.

\section{Conflicts of interest}

The authors declare no conflict of interest, financial or otherwise.

\section{References}

1. Singh AD, Topham A (2003) Incidence of uveal melanoma in the United States: 19731997. Ophthalmology 110: 956-961.

2. Hu DN, Yu GP, McCormick SA, Schneider S, Finger PT (2005) Population-based incidence of uveal melanoma in various races and ethnic groups. Am J Ophthalmol 140: 612-617. [Crossref] 
3. Shields CL, Kaliki S, Cohen MN, Shields PW, Furuta M, et al. (2015) Prognosis of uveal melanoma based on race in 8100 patients: the 2015 Doyne lecture. Eye (London) 29: 1027-1035. [Crossref]

4. Scott JF, Vyas R, Galvin J, Gotow E, Fiessinger L, et al. (2018) Primary bilateral uveal melanoma: a population-based study and systematic review. Clin Exp Ophthalmol 46: 502-510. [Crossref]

5. Singh AD, Shields CL, Shields JA, De Potter P (1996) Bilateral primary uveal melanoma. Bad luck or bad genes? Ophthalmology 103: 256-262. [Crossref]

6. Wiesinger H, Phipps GH, Guerry D (1959) Bilateral melanoma of the choroid associated with leukemia and meningioma. Arch Ophthalmol 62: 889-893. [Crossref]

7. Virgili G, Gatta G, Ciccolallo L, Capocaccia R, Biggeri, A, et al. (2008) Survival in patients with uveal melanoma in Europe. Arch Ophthalmol 126: 1413-1418. [Crossref]

8. Singh AD, Turell ME, Topham AK (2011) Uveal melanoma: trends in incidence, treatment, and survival. Ophthalmology 118: 1881-1885. [Crossref]

9. Chew AL, Spilsbury K, Isaacs TW (2015) Survival from uveal melanoma in Western Australia 1981-2005. Clin Exp Ophthalmol 43: 422-428. [Crossref]

10. Diener-West M, Reynolds SM, Agugliaro DJ, Caldwell R, Cumming K, et al. (2005) Development of metastatic disease after enrollment in the COMS trials for treatment of choroidal melanoma: collaborative ocular melanoma study group report no. 26 . Arch Ophthalmol 123: 1639-1643. [Crossref]
11. Singh AD, Borden EC (2005) Metastatic uveal melanoma. Ophthalmol Clin North Am 18: 143-150. [Crossref]

12. Mariani P, Piperno-Neumann S, Servois V, Berry MG, Dorval T, et al. (2009) Surgical management of liver metastases from uveal melanoma: 16 years' experience at the Institut Curie. Eur J Surg Oncol 35: 1192-1197. [Crossref]

13. Rietschel P, Panageas KS, Hanlon C, Patel A, Abramson DH, et al. (2005) Variates of survival in metastatic uveal melanoma. J Clin Oncol 23: 8076-8080.

14. Goh AY, Layton CJ (2016) Evolving systemic targeted therapy strategies in uveal melanoma and implications for ophthalmic management: a review. Clin Exp Ophthalmol 44: 509-519. [Crossref]

15. Carvajal RD, Schwartz GK, Tezel T, Marr B, Francis JH, et al. (2016) Metastatic disease from uveal melanoma: treatment options and future prospects. Br JOphthalmol 101: 38-44. [Crossref]

16. Gonder JR, Shields JA, Albert DM, Augsburger JJ, Lavin PT, et al. (1982) Uveal malignant melanoma associated with ocular and oculodermal, melanocytosis. Ophthalmology 89: 953-660. [Crossref]

17. Eide N, Garred O, Beiske K, Fodstad O (2016) Bilateral uveal melanomas with differen gene expression detected with 7 years interval. Acta Ophthalmol 94: 99-102. [Crossref]

18. Yu MD, Maasomian B, Shields JA, Shields CL (2020) BAPl germline mutation associated with bilateral primary uveal melanoma. Ocul Oncol Pathol 6: 10-14. [Crossref]

Copyright: (C2020 Ebert FG. This is an open-access article distributed under the terms of the Creative Commons Attribution License, which permits unrestricted use, distribution, and reproduction in any medium, provided the original author and source are credited. 